\title{
DESENVOLVIMENTO DE UM AMBIENTE VIRTUAL DE APRENDIZAGEM PARA APOIAR O USO DA TECNOLOGIA ASSISTIVA POR PROFESSORES ${ }^{(*)}$
}

\author{
David dos Santos Calheiros \\ Enicéia Gonçalves Mendes \\ Babette de Almeida Prado Mendonza $a^{(* *)}$
}

\section{INTRODUÇÃO}

As pessoas que possuem comprometimentos funcionais, em muitos casos, podem ter sua plena participação social garantida por meio da utilização de recursos de Tecnologia Assistiva (TA), que objetivam promover a funcionalidade, relacionada à atividade, visando proporcionar maior autonomia, independência, qualidade de vida e inclusão social.

A implementação dos recursos de TA também pode fazer uma grande diferença na escolarização de estudantes com deficiência. Entretanto, o uso continuado destes por professores é considerado desafiador, pois embora eles se apropriem do conhecimento sobre TA quando submetidos a programas de formação continuada e a serviços de apoio - como do tipo consultoria colaborativa, ${ }^{1}$ em geral não dão prosseguimento ao uso desses recursos quando concluídas essas formações e cessados os suportes (DOUNIS, 2013; FRANÇANI; SIMÕES; BRACCIALLI, 2009; HUMMEL, 2012; LOURENÇO, 2012; PELOSI, 2008; SCHIRMER et al., 2010; TOYODA; CRUZ; LOURENÇO, 2009).

Para suprir essa lacuna, Lourenço (2012) sugere a implementação de um serviço de suporte permanente na escola de profissionais com expertise na área da TA. Apesar da relevância dessa

\footnotetext{
${ }^{(*)}$ Esta pesquisa recebeu financiamento da Fundação de Amparo à Pesquisa do Estado de São Paulo (Fapesp).

** David S. Calheiros. Doutorando em Educação Especial pelo Programa de Pós-graduação em Educação Especial da Universidade Federal de São Carlos (UFSCar). Professor auxiliar da Universidade Estadual de Ciências da Saúde de Alagoas (UNCISAL), Maceió, AL, Brasil.

Enicéia G. Mende. Pós-Doutorado Sorbonne - Universite Paris V - Rene Descartes. Doutora em Psicologia pela Universidade São Paulo (USP). Professora titular da Universidade Federal de São Carlos (UFSCar), São Carlos, SP, Brasil.

Babette A. P. Mendonza. Mestra em Comunicação Social pela Universidade Metodista de São Paulo (UMESP) e Designer Instrucional da modalidade educação à distância, São Carlos, SP, Brasil.

${ }^{1}$ A consultoria colaborativa é uma estratégia destinada a resolver problemas educacionais relacionados ao processo de inclusão escolar. Esse trabalho envolve a participação de profissionais especializados (por exemplo, de terapeuta ocupacional, psicólogo, fisioterapeuta, fonoaudiólogo, assistente social, etc.) e professores da escola comum (MENDES; ALMEIDA; TOYODA, 2011), oportunizando a construção de habilidades profissionais por meio do trabalho colaborativo - que se fundamenta na ajuda mútua e na igualdade dos papéis de atuação.
} 
recomendação, precisa-se pensar na operacionalização desse serviço, em virtude dos seguintes fatores: a) Escassez de profissionais especializados na área da TA com conhecimentos aplicados ao contexto educacional (PENA; ROSOLÉM; SIRENA, 2008; SILVA, 2007; TOYODA; LOURENÇO, 2008); b) resistência em relação à contratação desses profissionais com verbas da área de Educação para atuar na rede básica de ensino regular (ROCHA, 2013); c) Elevado custo dos programas de formação, oferecidos na modalidade presencial (HACK, 2011; LEMOS; CARDOSO; PALACIOS, 2005).

Mediante essa situação, a modalidade à distância constitui-se como uma possibilidade de grande relevância para o desenvolvimento de um serviço de suporte em TA, pois permite, de forma mais econômica, que especialistas assessorem um maior número de professores no uso de TA, fornecendo ao mesmo tempo prestação de serviço e formação. Além do mais, Teixeira et al. (2010) argumentam que a formação à distância favorece um espaço de forte dinamicidade e interatividade, pois faculta a qualquer pessoa estar conectado em qualquer local desejado, independente da localização geográfica que esteja.

Partindo-se desse contexto, este estudo teve por objetivo descrever o processo de desenvolvimento de um ambiente virtual de aprendizagem (AVA), construído especialmente para apoiar o uso de recursos de TA por professores de estudantes com paralisia cerebral (PC), e avaliar as potencialidades e os limites desse AVA em um serviço de consultoria colaborativa à distância em TA.

\section{ASPECTOS METODOLÓGICOS}

Para este estudo foi adotada a abordagem qualitativa de pesquisa com um enfoque exploratório. Participaram do serviço de consultoria colaborativa seis professoras que atuavam em salas de recursos multifuncionais (SRM), ${ }^{2}$ sendo que duas delas formaram casos individuais e as outras quatro professoras formaram duas duplas de trabalho - cada uma delas acompanhando o caso de um estudante com PC, que necessitasse do uso de recursos de TA, e recebendo um suporte à distância (via AVA) de três especialistas da área em questão. Assim, foram constituídos quatro estudos de caso, a saber: caso da Professora 1, caso da Professora 2, caso da Dupla 1, caso da Dupla 2.

\footnotetext{
${ }^{2}$ A SRM é um espaço que possui um conjunto de equipamentos de TA, informática, mobiliários, materiais pedagógico e de acessibilidade, destinados a apoiar a organização e a oferta do atendimento educacional especializado - para o público-alvo da Educação Especial,de forma complementar ou suplementar.
} 
O AVA foi desenvolvido durante o curso da pesquisa - pelos pesquisadores, com o intuito de facilitar a comunicação/colaboração entre as professoras e especialistas na área de TA, visando assegurar o uso da TA no processo de escolarização de estudantes com paralisia cerebral.

O AVA foi avaliado por meio do Questionário de Avaliação Final do Serviço de Consultoria Colaborativa à Distância em Tecnologia Assistiva (AFCC), que havia sido elaborado pelos pesquisadores e submetido à validação de conteúdo por juízes' integrantes do Grupo de Pesquisa sobre Formação de Recursos Humanos e Ensino em Educação Especial (GP-FOREESP), pesquisadores, doutorandos, mestrandos e graduandos da área de Educação Especial da UFSCar.

Em termos técnicos, o questionário AFCC é autoadministrável e possui duas partes. $\mathrm{Na}$ primeira parte, os participantes deveriam expressar o seu grau de satisfação ou insatisfação com a consultoria prestada e de uma maneira específica com o AVA, por meio de uma escala likert atribuindo notas de 1 a 5 . Os significados estabelecidos para cada valor são apresentados na Figura 1.

Figura 1. Grau de Satisfação ou Insatisfação com o Serviço de Consultoria

\begin{tabular}{lllll}
\hline Insatisfatório & Pouco Satisfatório & $\begin{array}{l}\text { Regularmente } \\
\text { Satisfatório }\end{array}$ & Satisfatório & Muito Satisfatório \\
\hline 1 & 3 & 4 & 5 \\
\hline
\end{tabular}

Fonte: Elaboração própria (2014).

$\mathrm{Na}$ segunda parte, os participantes forneceriam informações mais descritivas sobre os diferentes aspectos do serviço oferecido, inclusive sobre o AVA.

Os resultados foram tratados através da técnica de análise de conteúdo, especificamente a temática (BARDIN, 2011). De uma maneira particular, em relação aos dados da escala de Likert, presente na parte A do questionário AFCC, também foi realizado uma análise descritiva por meio de frequências absolutas.

\section{RESULTADOS}

\subsection{Desenvolvimento do ambiente virtual de aprendizagem}

Considerando que a construção do ambiente virtual de pesquisa envolveria conhecimentos técnicos e especializados na área de informática, contratou-se o serviço de um designer instrucional para assessorar esse intento. Em seguida, deu-se início a busca por selecionar o ambiente virtual que estivesse disponível no mercado - e que melhor respondesse às necessidades do desenho metodológico da pesquisa em questão. 
O ambiente selecionado foi o Moodle, por apresentar um sistema de simples operacionalização e eficácia, que dispõe de ferramentas para conteúdo e para concretização de atividades on-line, bem como de instrumentos para comunicação síncrona ou assíncrona. De uma maneira particular, optou-se por utilizar o Moodle do GP-FOREESP, Moodle do Portal Kunlaborado do GP-FOREESP (http://kunlaborado.com.br/portal/).

Posteriormente, teve início ao processo de confecção do logotipo para dar identidade visual ao projeto, e do nome do ambiente da pesquisa. No que se refere ao logotipo, pensou-se em uma figura que pudesse representar o fio condutor dessa pesquisa: a colaboração. Em relação ao nome do ambiente, este deveria ser curto e, ao mesmo tempo, necessitaria também contemplar a dimensão do serviço ao qual se destinaria. Assim, estabeleceu-se o seguinte termo: ConsulTecAssistiva. Contudo, por uma questão estética - o nome do ambiente foi reduzido para que coubesse dentro do logotipo. Desse modo, o ambiente foi denominado de "CTA", que é a sigla do termo ConsulTecAssistiva.

Figura 2. Logomarca do Ambiente de Pesquisa

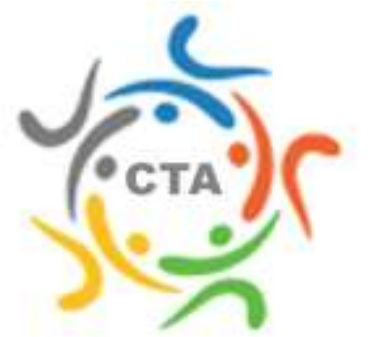

Fonte: Elaboração própria (2014).

O passo seguinte foi esquematizar o formato da navegação dos participantes pelo ambiente virtual do CTA. A organização foi delineada em etapas e baseou-se nos procedimentos de coleta de dados: I. Caracterização da Demanda de Caso para Consultoria Colaborativa; II. Intervenção via Serviço de Consultoria Colaborativa; III. Avaliação das Ações e do Serviço de Consultoria Colaborativa. Além disso, levou-se em consideração os seguintes aspectos:

- Em geral, as pessoas gostam de contar histórias, dessa maneira seria possível conduzir as narrativas das professoras e ao mesmo tempo permitir que elas se sentissem mais "ativas" no processo da pesquisa. 
- Ao narrar, as professoras poderiam já ir exercitando a sua observação e sua capacidade crítica sobre o assunto, tal fato também poderia auxiliar no empoderamento que a consultoria colaborativa visa proporcionar aos envolvidos.

- A pesquisa poderia se caracterizar como metodologia de atendimento on-line, ou resolução de problemas a partir de interação on-line e de forma colaborativa.

De uma maneira geral, o ambiente CTA foi pensado tendo como base a facilitação do acesso à informação; a facilidade para a comunicação entre as professoras e consultoras (com intermediação do pesquisador); facilidade do acesso às orientações e para permitir o envio e organização de materiais para facilitar a consultoria; bem como a facilitação da comunicação entre as próprias consultoras. Para atender essas premissas, o ambiente CTA apresenta uma variedade de ferramentas (recursos e links para arquivo ou website, tarefa, bate-papo, fórum, dentre outros), envolvendo múltiplas funções de compartilhamento de arquivos e de recursos textuais e multimídia, bem como mecanismos para a comunicação, execução e acompanhamento de tarefas.

Para auxiliar o processo de navegação no ambiente CTA e o devido uso das ferramentas, foi desenvolvido um vídeo tutorial (legendado) com orientações pormenorizadas. Este tutorial poderia ser visualizado pelas participantes, a qualquer momento, já que o mesmo estava disponível para consulta no próprio ambiente CTA. Ademais, tanto o pesquisador, quanto o designer instrucional poderiam ser consultados para solucionar as dúvidas surgidas.

O período de construção/adequação do ambiente virtual da pesquisa durou cerca de dois meses, mas seu aperfeiçoamento se fez durante todo o período de realização da pesquisa - a partir das sugestões de mudanças das professoras, consultoras e do próprio pesquisador.

Construído o AVA, o ambiente CTA teve o seu conteúdo e formato avaliado por juízes, integrantes do GP-FOREESP.

\section{ESTRUTURA ORGANIZACIONAL DO AMBIENTE CTA}

O ambiente CTA foi estruturado em duas partes: 1. Área de Informações gerais sobre a pesquisa; 2. Área de Operacionalização do Serviço de Consultoria Colaborativa em Tecnologia Assistiva.

Informações detalhadas sobre cada uma delas são apresentadas a seguir. 


\section{Área de Informações gerais sobre a pesquisa}

$\mathrm{Na}$ Área de Informações gerais sobre a pesquisa, foram disponibilizados as participantes os principais informes, considerados como essenciais para o início do envolvimento na pesquisa. Assim, por uma questão didática, foi construído um trajeto dividido em quatro estações, como se pode observar na Figura 3:

Figura 3. Área de Informações Gerais Sobre a Pesquisa do Ambiente CTA

Fonte: Elaboração própria (2014).

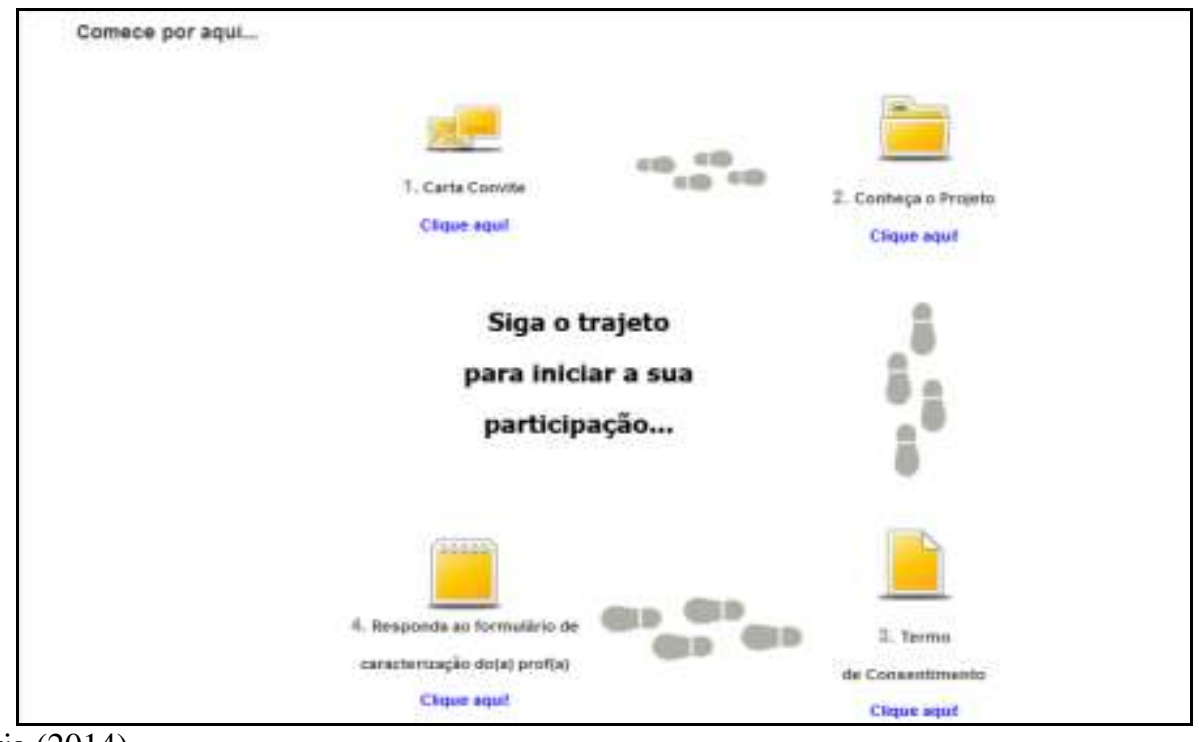

Na primeira estação, as professoras de SRM e as consultoras de TA tiveram acesso a Carta Convite (ver apêndice B), que formalizava a participação na pesquisa.

Na segunda estação, foi disponibilizada uma síntese das informações do projeto de pesquisa e anexado a ele constava o parecer consubstanciado do CEP/UFSCar (ver anexo B). Em seguida, as participantes deveriam ler o termo de consentimento livre e esclarecido, que estava disponível na terceira estação, e assinalar a sua opção de concordância ou discordância com as informações daquele documento, nos campos indicados. Ao concordar, a participante atestava o seu consentimento em participar da pesquisa. O pesquisador poderia ter o acesso da informação de "aceite" ou "não aceite" do TCLE no relatório individual de cada participante, conforme se pode visualizar na resposta da Professora de SRM 1, exibida na Figura 4.

Figura 4. Manifestação do Consentimento Livre e Esclarecido

\section{Escolha: Termo de Consentimento Livre e Esclarecido}

Respondido: 'Aceito'. Atualizado sexta, 28 março 2014, 06:33

Fonte: Elaboração própria (2014). 
Por último, mais especificamente na quarta estação, as professoras de SRM preencheram o Formulário para Caracterização dos Professores de Salas Recursos Multifuncionais (ver Anexo A), como forma do pesquisador obter conhecimento sobre os seus perfis profissionais e pessoais. Este preenchimento, não se fez necessário para as consultoras de TA, pois as suas informações estavam disponíveis para consulta na plataforma Lattes. Vale esclarecer que o Formulário para Caracterização dos Professores de Salas Recursos Multifuncionais foi incorporado ao processador de texto on-line Google Docs, justificado pela sua capacidade de organizar e tabular as informações.

\section{1. Área de Operacionalização do Serviço de Consultoria Colaborativa em Tecnologia Assistiva}

Esta área foi configurada de forma a proporcionar as professoras de SRM uma sequência de etapas, no intuito de favorecer-lhes um melhor entendimento da dinâmica de implementação desse serviço. Em síntese, este espaço permitiria as professoras de SRM apresentarem as suas demandas, interagirem com as consultoras de TA - por meio da mediação do pesquisador, aplicarem as orientações, retornarem com o feedback das suas aplicações e, por fim, avaliarem a prestação do serviço oferecido. Desse modo, três etapas foram constituídas e estas são apresentadas na Figura 5: Figura 5. Área de Operacionalização do Serviço de Consultoria Colaborativa em Tecnologia Assistiva

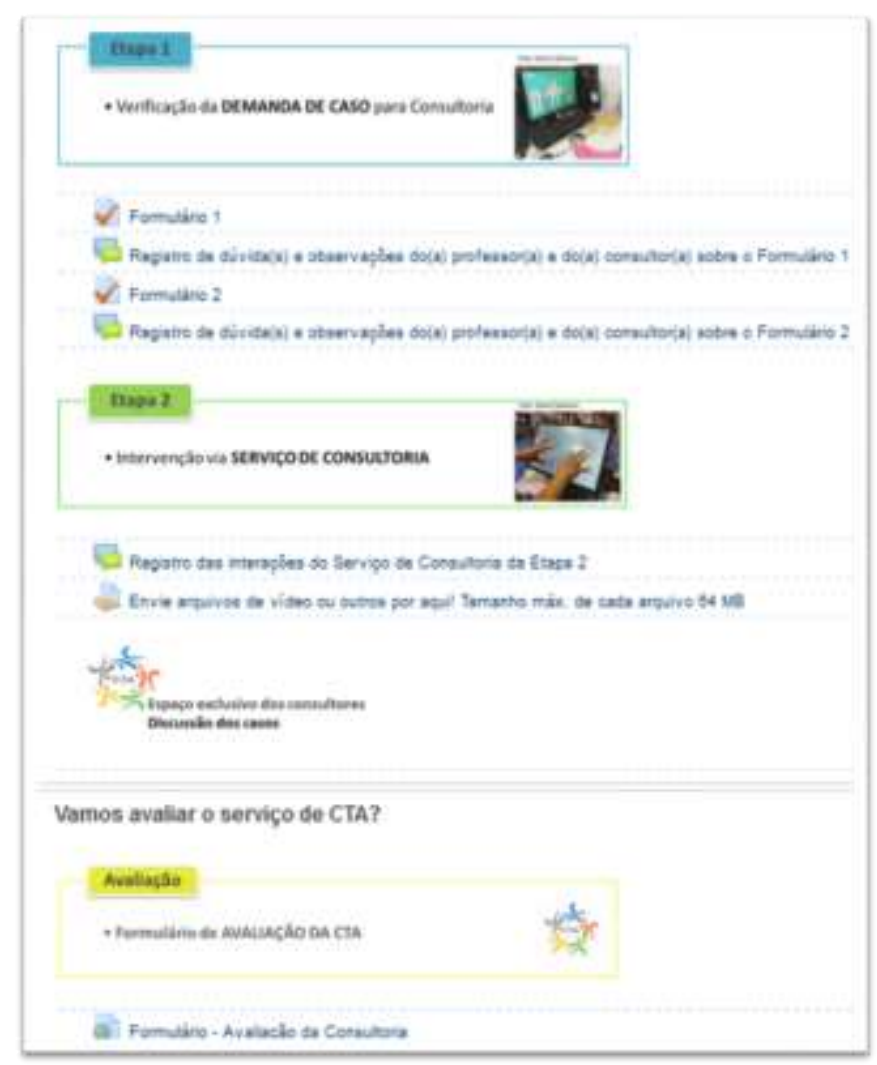

Fonte: Elaboração própria (2014). 
A Etapa 1, denominada de Verificação da Demanda de Caso para Consultoria, principia o serviço de consultoria colaborativa em TA. Nela as professoras de SRM deveriam informar, por meio do preenchimento do Questionário sobre Demanda de Caso para Consultoria Colaborativa à Distância em Tecnologia Assistiva (incorporado ao próprio Moodle nos Formulários 1 e 2), as suas dificuldades em utilizar a tecnologia assistiva, exclusivamente aquelas relacionadas ao processo educativo de estudantes com PC. Para tanto, cada professora ou dupla de professoras SRM deveria selecionar e descrever o caso de um de seus estudantes com PC para receber o apoio desse serviço especializado.

Os dados enviados serviriam como base para as consultoras planejarem as propostas de intervenções. Caso houvesse dúvidas ou, até mesmo, necessidade de completar as informações contidas nos Formulários 1 e 2, as professoras de SRM e as consultoras de TA poderiam utilizar os fóruns de discussão para se comunicar. Além disso, as professoras de SRM poderiam apenas manter contato com as consultoras de TA e, nunca, com as outras professoras de SRM. Da mesma forma, foi vedada a qualquer professora visualizar as discussões de outros casos, a não ser o seu próprio caso de estudo.

A Etapa 2, intitulada de Intervenção via Serviço de Consultoria, foi a fase onde a dinâmica da consultoria propriamente ocorreu. Nesse espaço, as interações entre as participantes deveriam ter um caráter mais propositivo, no sentido de se formular colaborativamente propostas específicas que respondessem as necessidades dos casos escolhidos. Depois de formuladas as propostas de soluções, as professoras de SRM deveriam aplicar as orientações e, em seguida, retornar com o feedback das suas aplicações, mesmo os resultados delas sendo positivos ou negativos.

Todo esse processo de interação da Etapa 2 deveria ser registrado e, para isso, havia um fórum de discussão, nomeado de Registro das Interações do Serviço de Consultoria da Etapa 2, no qual as professoras de SRM poderiam se comunicar com as consultoras de TA e ter acesso aos registros e informações do seu caso em específico. De igual forma, também havia um espaço para interação exclusiva entre as consultoras, que assim foi denominado Espaço exclusivo dos consultores: Discussão dos casos. Acompanhando esse espaço de interação, disponibilizou-se uma ferramenta para envio de registros, vídeos e fotos dos alunos - alvo da intervenção.

A última etapa da Área de Operacionalização do Serviço de Consultoria Colaborativa em Tecnologia Assistiva é a Etapa 3, designada de Avaliação do Serviço de Consultoria, nela tanto as professoras, quanto as consultoras avaliaram o serviço oferecido, quando este chegou ao fim. Para tanto, deveriam responder o Questionário de Avaliação Final do Serviço de Consultoria Colaborativa à Distância em Tecnologia Assistiva, que foi incorporado ao ambiente virtual. 


\subsection{Avaliação do ambiente "CTA": Perspectiva das consultoras}

O ambiente virtual da pesquisa CTA foi avaliado pelas consultoras como sendo "satisfatório" e "muito satisfatório" em quase todos os itens de análise. Tais resultados podem ser visualizados no Quadro 1:

Quadro 1. Avaliação das consultoras sobre o ambiente CTA

\begin{tabular}{|c|c|c|c|c|c|}
\hline \multirow{2}{*}{ Itens de análise da categoria: ambiente virtual da pesquisa } & \multicolumn{5}{|c|}{ Escores do Questionário AFCC } \\
\hline & 1 & 2 & 3 & 4 & 5 \\
\hline O Acesso ao Ambiente & -- & -- & -- & 3 & -- \\
\hline Clareza do vídeo tutorial do ambiente da pesquisa & -- & -- & -- & 1 & 2 \\
\hline A estrutura organizacional do ambiente & -- & -- & -- & 2 & 1 \\
\hline O Funcionamento do ambiente & -- & -- & -- & 2 & 1 \\
\hline A capacidade de download e upload do ambiente & -- & -- & 1 & -- & 2 \\
\hline O Suporte Técnico do Ambiente & -- & -- & -- & 1 & 2 \\
\hline
\end{tabular}

Fonte: Elaboração própria (2014).

O único aspecto do ambiente CTA que teve um conceito diferente foi o da capacidade de download e upload, que embora tenha sido avaliado como "muito satisfatório" por duas das consultoras, obteve também apreciação de "regularmente satisfatório" - pela terceira consultora. Na perspectiva dessa última, houve complicações do ambiente CTA para baixar/visualizar os vídeos que as professoras postavam em relação ao processo de implementação da consultoria. A seguir, são expostas duas ilustrações envolvendo esse contexto:

Não consegui responder para a Dupla 1. Está travando. Os vídeos não abriram. Vou tentar em outro computador (Consultora 2 - Fonte: Ambiente CTA).

Não estou conseguindo abrir os vídeos. Eles carregam, mas ficam pretos e não mostram imagens (Consultora 3 - Fonte: Ambiente CTA).

Para solucionar essa problemática, o suporte técnico do ambiente CTA fez algumas recomendações que poderiam ser seguidas para melhorar o desempenho. Dentre as recomendações estavam: a) verificar a conexão da internet - que talvez estivesse lenta; b) trocar o navegador Mozilla Firefox foi indicado como o mais eficaz. Por meio dessas orientações, foi possível diminuir as situações de travamentos dos vídeos, no entanto em determinados momentos esse problema ainda persistia.

Quando persistido os problemas, o suporte técnico analisava as particularidades e tentava investigar onde estavam os empecilhos. De acordo com Moreira (2010), é difícil precisar onde está o problema, pois são muitas as variáveis que estão envolvidas no uso de um AVA, que pode sofrer influência do tipo do servidor, das configurações adequadas dos computadores, do provedor externo, dos casos particulares de cada usuário, etc. 
Mediante esse contexto, considera-se importante ao início de qualquer serviço destinado a utilizar ambientes virtuais, entender não apenas as competências e as experiências individuais dos participantes com o uso do computador e EAD (Educação à Distância) - conforme foi realizado nessa pesquisa, mas compreender o contexto geral do usuário, para saber a capacidade técnica da internet que ele fará uso, as configurações técnicas do computador, as necessidades individuais de cada caso, dentre muitas outras questões.

Retomando a análise do Quadro 1, acredita-se que os resultados exitosos, obtidos nos itens: acesso ao ambiente, clareza do vídeo tutorial do ambiente da pesquisa, estrutura organizacional do ambiente, funcionamento do ambiente e no suporte técnico do ambiente, devem-se em grande medida a todo um trabalho anterior de planejamento prévio de construção do ambiente, bem como do processo de validação que foi executado por juízes, visando o aperfeiçoamento desse ambiente.

O bom desempenho do ambiente CTA também foi mencionado pelas consultoras na parte descritiva do questionário AFCC, as quais destacaram como suas principais características a fácil manipulação e a promoção de um espaço propício de interação, conforme pode ser visto a seguir:

O ambiente propiciou a interação necessária entre o grupo de consultoras [...] (Consultora 1Fonte: Questionário AFCC).

Foi bastante positiva, fácil de manipular (Consultora 2 - Fonte: Questionário AFCC).

No processo de construção do ambiente CTA, a interação e a fácil manipulação foram consideradas variáveis norteadoras para a implementação do serviço de consultoria. Tais prerrogativas partiram do entendimento de que os ambientes virtuais deveriam promover o diálogo e a colaboração entre os seus interlocutores (no caso do ambiente CTA: consultoras e professoras), bem como incitar a construção do conhecimento coletivo por meio de ferramentas tecnológicas apropriadas (ALVES, 2009).

\subsection{Avaliação do ambiente "CTA": Perspectiva das professoras}

De uma maneira semelhante, as professoras avaliaram o ambiente CTA como sendo "satisfatório" e "muito satisfatório" em quase todos os itens de análise, conforme se pode visualizar logo a seguir:

Quadro 2. Avaliação das professoras sobre o ambiente CTA

\begin{tabular}{|c|c|c|c|c|c|}
\hline \multirow{2}{*}{$\begin{array}{l}\text { Itens de análise da categoria: } \\
\text { ambiente virtual da pesquisa }\end{array}$} & \multicolumn{5}{|c|}{ Escores do Questionário AFCC } \\
\hline & 1 & 2 & 3 & 4 & 5 \\
\hline O Acesso ao Ambiente & -- & -- & -- & 1 & 3 \\
\hline Clareza do vídeo tutorial do ambiente da pesquisa & -- & -- & -- & 1 & 3 \\
\hline A estrutura organizacional do ambiente & -- & -- & -- & 2 & 2 \\
\hline O Funcionamento do ambiente & -- & -- & -- & 1 & 3 \\
\hline A capacidade de download e upload do ambiente & -- & -- & 1 & -- & 3 \\
\hline O suporte técnico do ambiente & -- & -- & 1 & 1 & 2 \\
\hline
\end{tabular}


De acordo com a Quadro 2, embora o item capacidade de download e upload do ambiente CTA tenha sido assinalado como sendo "muito satisfatório" pela maior parte das professoras, ele também foi avaliado por uma dessas participantes com o conceito de "regularmente satisfatório". A explicação deste último fato pode ter relação com alguns empecilhos enfrentados no decorrer da consultoria envolvendo esse ambiente. A seguir, são apresentadas algumas dessas dificuldades:

Tentei várias vezes, mas não consegui abrir os vídeos. Será que há algum programa que preciso baixar? (Dupla 1 - Fonte: Ambiente CTA).

Estou postando por aqui [via e-mail] os arquivos, pois não estava conseguindo pela página da consultoria (Dupla 1 - Fonte: E-mail).

Acabo de tentar, mas não consigo [enviar os arquivos pelo ambiente CTA], acho que o vídeo é pesado. Se tiver alguma orientação, eu tento modificar o vídeo para mandar. Tenho três vídeos que acho interessante mandar, uso da comunicação multimodal: 1- aluno com pasta de comunicação alternativa; 2- comunicação por gestos e o próprio corpo e 3 - Libras com sinais isolado (Dupla 2 - Fonte: Ambiente CTA).

De acordo com os relatos, as professoras também enfrentaram problemas para visualizar/baixar vídeos e fazer upload de arquivos pelo ambiente CTA, essas problemáticas acabaram influenciando na dinâmica das atividades do serviço de consultoria. A primeira situação ocorreu devido à utilização de outros navegadores que não o recomendado pelo suporte técnico (Mozilla Firefox). Assim, quando as professoras passaram a utilizar esse navegador os problemas de visualização de vídeos foram contornados. A segunda problemática ocorreu devido à limitação do próprio Moodle de enviar arquivos com tamanho superior a $20 \mathrm{MB}$.

Levando em consideração esse problema, surgiu a necessidade de aumentar o limite de upload do ambiente CTA, para uma capacidade máxima de 64 MB - por arquivo enviado. Além disso, o suporte técnico do ambiente resolveu criar uma ferramenta tarefa dentro do próprio ambiente CTA para envio de arquivos. Segundo o suporte técnico:

Acho que a melhor forma seria eu criar uma ferramenta tarefa para envio de arquivo. Elas [professoras] poderiam gravar vários vídeos curtos - de 3 minutos, quantos forem necessários. Depois, enviariam pelo ambiente um por um (Suporte técnico - Fonte: E-mail).

Muito embora, essas mudanças tenham possibilitado o envio de arquivos com capacidades de até 64MB no ambiente CTA, elas não foram suficientes para potencializar esse ambiente no sentido de atender às demandas das professoras. Assim, outra estratégia teve que ser adotada para o envio de arquivos que excediam a capacidade do ambiente CTA, que foi a de utilizar o serviço de armazenamento de dados em nuvens (por exemplo, via OneDrive, Dropbox ou Google Drive), utilizando a ferramenta de compartilhamento de arquivos. 
Resgatando a análise do Quadro 2, é possível também constatar que o quesito suporte técnico do ambiente CTA teve respostas distintas, variando entre "regularmente satisfatório" assinalado por uma professora, "satisfatório" - assinalado por uma professora- e "muito satisfatório" - assinalado por duas professoras. A resposta "regularmente satisfatório" pode estar relacionada com os problemas do ambiente CTA, implicados na limitação do próprio Moodle e na consequente impossibilidade de mudança por parte do suporte técnico desse ambiente. Do contrário, os escores mais elevados dados ao suporte técnico se justificam, talvez, pela sua capacidade de pronto atendimento e de diálogo - conferida pelas participantes no processo de consultoria.

Os resultados "satisfatório" e "muito satisfatório", obtidos nos demais quesitos: acesso ao ambiente, clareza do vídeo tutorial do ambiente da pesquisa, estrutura organizacional do ambiente, funcionamento do ambiente, devem-se fundamentalmente ao trabalho anterior de elaboração do ambiente, associado ao processo de validação dos juízes.

As experiências das professoras com o ambiente CTA, relatadas na parte descritiva do questionário AFCC, confirmam o efeito positivo desse ambiente virtual como um espaço propício para a implementação do serviço de consultoria colaborativa à distância em TA. Confira essas experiências:

Foi uma experiência muito satisfatória. A todo o momento recebi orientações adequadas e tive facilidade em realizar cada etapa solicitada devido à orientação clara e precisa. Mesmo com as minhas limitações para utilizar todos os recursos do computador, não tive dificuldade de realizar o que me foi solicitado devido às explicações enviadas e o vídeo tutorial. Nos momentos que não concordei com algo ou que tive dificuldade, recebi novas orientações, essa possibilidade de dialogar sobre o ambiente virtual foi muito positiva (Dupla 2 - Fonte: Questionário AFCC).

As informações estavam claras e objetivas. Posso dizer que a experiência foi positiva (Professora 2 - Fonte: Questionário AFCC).

Assim, as orientações/explicações claras e precisas, associadas ao vídeo tutorial e a capacidade de diálogo, constituíram-se como alguns dos aspectos essenciais para o fator de sucesso do ambiente CTA. Esse fato corrobora com os postulados de Holmberg (1985), ao mencionar que embora os usuários se encontrem em ambientes virtuais que não primam por ter uma contínua e imediata supervisão presencial, estes se beneficiam do planejamento, orientação e acompanhamento de uma organização tutorial. Desse modo, destaca-se a importância de qualquer serviço de consultoria colaborativa à distância prezar por essas características, para que possa alcançar êxito. 


\section{CONSIDERAÇÕES FINAIS}

A presente pesquisa teve objetivo descrever o processo de construção de um AVA, bem como avaliar as potencialidades e os limites desse ambiente em um serviço de consultoria colaborativa estabelecido entre professoras de salas de recursos multifuncionais e especialistas na área de TA. Por meio dos procedimentos adotados, foi possível atingir a finalidade desse estudo e, em linhas gerais, as evidências encontradas apontam que o ambiente virtual CTA se constituiu como um espaço propício para a implementação de serviços de consultoria colaborativa à distância em TA.

O estudo representa uma tentativa de avançar na produção de conhecimento sobre formação de recursos humanos, introduzindo uma inovação que seria oferecer prestação de serviços e formação à distância. Num contexto de um país continental como o Brasil, no qual a demanda por formação de recursos humanos na área de TA é enorme, os recursos e ferramentas da educação à distância podem contribuir para socializar o conhecimento e favorecer a escolarização dos estudantes com deficiência.

\section{REFERÊNCIAS}

ALVES, A. C. J. Percepção de alunos com paralisia cerebral sobre o uso de recursos de tecnologia assistiva na escola regular. 2009. 168f. Dissertação (Mestrado em Educação Especial) - Universidade Federal de São Carlos, São Carlos, 2009.

BARDIN, L. Análise de Conteúdo. São Paulo: Edições 70, 2011.

DOUNIS, A. B. Atividade docente e inclusão: as mediações produzidas pela Consultoria Colaborativa. 2013. $180 \mathrm{f}$. Dissertação (Mestrado em Educação) - Universidade Federal de Alagoas, Maceió, 2013.

FRANÇANI, C. O.; SIMÕES, E. M.; BRACCIALLI, L. M. P. Tecnologia assistiva: desenvolvimento de recursos de baixo custo. Revista Ciência em Extensão, São Paulo, v. 5, n. 2, p. 108, 2009.

HACK, J. R. Introdução à educação à distância. Florianópolis: LLV/CCE/UFSC, 2011.

HOLMBERG, B. Educación a distancia: situación y perspectivas. Buenos Aires: Kapeluz, 1985.

HUMMEL, E. I. Formação de professores das salas de recursos multifuncionais para o uso da tecnologia assistiva. 2012. 231f. Tese (Doutorado em Educação) - Faculdade de Filosofia e Ciências, Unesp, Marília, 2012.

LEMOS, A.; CARDOSO, C.; PALACIOS, M. Revisitando o Projeto Sala de Aula no Século XXI. In: ARAÚJO, B.; FREITAS, K. S. (Orgs.) Educação a Distância no contexto brasileiro: algumas experiências da UFBA. Salvador: ISP/UFBA, 2005, p.09-29.

LOUREÇO, G. F. Avaliação de um programa de formação sobre recursos de alta- tecnologia assistiva e escolarização. 2012. 258f. Tese (Doutorado em Educação Especial) - Centro de Ciências Humanas, Universidade Federal de São Carlos, 2012.

MOREIRA, L. Dúvidas e problemas no uso do Moodle. Disp.: 〈https://moodle.org/mod/forum/view.php?id=2404〉. Acesso: 20 jan. 2015.

PELOSI, M. B. Inclusão e Tecnologia Assistiva. 2008. 303f. Tese (Doutorado em Educação) - Centro de Educação e Humanidades, UERJ, Rio de Janeiro, 2008. 
PENA, F. F.; ROSOLÉM, F. C.; ALPINO, A. M. S. Contribuição da Fisioterapia para o bem-estar e a participação de dois alunos com Distrofia Muscular de Duchenne no ensino regular. Revista Brasileira de Educação Especial, Marília, v. 14, N. 3, p. 447-462, 2008.

ROCHA, A. N. D. C. Recursos e estratégias da tecnologia assistiva a partir do ensino colaborativo entre os profissionais da saúde e da educação. 2013. 210f. Tese (Doutorado em Educação) - Faculdade de Filosofia e Ciências, UNESP, Marília, 2013.

SCHIRMER, C. R.; ARAÚJO, C. A.; WALTER, C. F.; NUNES, L. R. O. P. Formação continuada em serviço de professores: uma proposta de colaboração entre educação especial, educação comum e clínica. . In: IV CONCRESSO BRASILEIRO DE EDUCAÇÃO ESPECIAL, 4, 2010, São Carlos. Anais... São Carlos: UFSCar, 2010. 1 CD-ROM.

SILVA, C. R. B. A formação do fonoaudiólogo: desafios e perspectivas para a educação inclusiva. 2007. 118f. Dissertação (Mestrado em Educação) - Centro de Ciências Sociais Aplicadas, PUC, Campinas, 2007.

TEIXEIRA, A. C. et al. Como o ciberespaço coloca fim à educação a distância. In: MACHADO, G. C. M. (Org.). Educação e ciberespaço: estudos, propostas e desafios. Aracaju: Virtus Editora, 2010, p. 182-207.

TOYODA, C. Y.; CRUZ, D. M. C.; LOURENÇO, G. F. Tecnologia assistiva de baixo custo: relato de consultoria colaborativa. In: V CONGRESSO BRASILEIRO MULTIDISCIPLINAR DE EDUCAÇÃO ESPECIAL, 5., 2009, Londrina. Anais... Londrina: UEL, 2009. 1 CD-ROM.

TOYODA, C. Y.; LOURENÇO, G. F. Educação inclusiva: o contexto da terapia ocupacional. In: ALMEIDA, M. A.; MENDES, E. G; HAYASHI, M. C. P. I. Temas em Educação Especial: múltiplos olhares. Araraquara, SP: Junqueira \& Marin; Brasília: Capes - Proesp, 2008. p. 44-52. 


\section{RESUMO}

A Tecnologia assistiva (TA) pode fazer uma grande diferença na escolarização de estudantes com deficiência. O objetivo desse estudo é descrever o desenvolvimento de um ambiente virtual de aprendizagem (AVA) e avaliar as potencialidades e os limites desse AVA em um serviço de consultoria colaborativa em TA. Participaram seis professoras e três especialistas na área de TA. O AVA foi avaliado por meio de um questionário. Para analisar os dados, empregou-se a análise de conteúdo temática e a análise descritiva por meio de frequências absolutas. Os resultados apontaram que o AVA desenvolvido se constitui como um espaço propício para a implementação de serviços de consultoria colaborativa em TA, revelando que é possível oferecer prestação de serviços e formação à distância nessa área.

Palavras-chave: Educação especial. Tecnologia assistiva. Ambiente virtual de aprendizagem.

\section{DEVELOPMENT OF A VIRTUAL LEARNING ENVIRONMENT TO SUPPORT TEACHERS TO USE ASSISTIVE TECHNOLOGY}

\section{ABSTRACT}

Assistive technology (AT) can make a big difference in the education of students with disabilities. The aim of this study is to describe the development of a virtual learning environment (VLE) and assess the potential and limits of AVA in a collaborative consulting service in AT. Six teachers and three experts in AT area has participated of this research. The AVA was evaluated through a questionnaire. To analyze the data, we used the thematic content analysis and descriptive analysis through absolute frequencies. The results showed that the AVA developed constitutes an appropriate environment for the implementation of collaborative consulting services in AT, revealing also that it is possible to offer services and e-learning in this area.

Keywords: Special education. Assistive technology. Virtual learning environment.

Submetido em Fev. 2016 Aprovado em Jun. 2016 